\title{
Detection of exercise induced changes in left ventricular performance by Doppler echocardiography
}

\author{
PATRICK J DALEY, * KIRAN B SAGAR, * B DAVID COLLIER, $\dagger$ \\ JOHN KALBFLEISCH, $\ddagger$ L SAMUEL WANN *
}

From the ${ }^{\star}$ Department of Medicine, Cardiology Section, $\dagger$ Department of Radiology, Nuclear Medicine Section, and $\ddagger$ Department of Anesthesiology, Medical College of Wisconsin, Milwaukee, Wisconsin, USA

SUMMARY A study was performed to test the hypothesis that Doppler echocardiographic measurement of ascending aortic blood flow can detect exercise induced changes in left ventricular performance during exercise in patients suspected of having ischaemic heart disease. Acceleration and peak velocity of flow and stroke volume were determined by non-imaging Doppler echocardiography in the suprasternal notch in 38 patients as they underwent simultaneous exercise radionuclide ventriculography. The patients were divided into four groups: group 1 had resting ejection fractions $\geqslant 50 \%$ and increased their ejection fractions $\geqslant 5 \%$ during exercise; group 2 had resting ejection fractions of $\geqslant 50 \%$ but the ejection fraction either fell or rose $<5 \%$ during exercise; group 3 had resting ejection fractions $<50 \%$ but the ejection fraction rose $\geqslant 5 \%$ during exercise; and group 4 had resting ejection fractions $<50 \%$ and the exercise ejection fraction either fell or rose $<5 \%$ during exercise. Acceleration, velocity, and stroke volume all rose significantly during exercise in group 1. Acceleration also increased in group 2 but to a lesser extent; velocity and stroke volume did not increase. In group 3 acceleration and velocity increased but to a lesser extent than in group 1; stroke volume did not increase. In group 4 velocity increased slightly during exercise but acceleration and stroke volume were unchanged.

Doppler echocardiography thus appears capable of detecting exercise induced changes in left ventricular performance and can identify normal and abnormal responses, as defined by radionuclide ventriculography.

Non-invasive evaluation of left ventricular performance both at rest and during exercise is highly desirable. Doppler echocardiography has proved to be an accurate means for non-invasively measuring the velocity of blood flow in the ascending aorta ${ }^{1}$ and can be used to measure left ventricular stroke volume $^{2-4}$ even during exercise. ${ }^{56}$ In addition to measuring stroke volume, Doppler echocardiography can be used to measure the acceleration and peak velocity of flow in the ascending

Requests for reprints to Dr L Samuel Wann, Cardiology Division, Medical College of Wisconsin, 8700 West Wisconsin Avenue, Milwaukee, Wisconsin 53226, USA.

Accepted for publication 15 April 1987 aorta. Acceleration and peak velocity have long been known to be directly related to left ventricular performance $^{7-10}$ and have even been found to be inversely related to the severity of coronary artery disease in patients undergoing cineangiography. ${ }^{1112}$

Thus the acceleration and peak velocity of blood flow in the ascending aorta are related to left ventricular performance and can be measured noninvasively both at rest and during exercise by Doppler echocardiography. The purpose of this study, therefore, was to test the hypothesis that Doppler echocardiographic measurement of blood flow in the ascending aorta can non-invasively detect exercise induced changes in left ventricular performance in patients suspected of having ischaemic heart disease. 


\section{Patients and methods}

\section{PATIENT SELECTION}

Doppler echocardiography was performed on 38 consecutive patients ( 7 women and 31 men; mean age 56, range 25-76) who were undergoing exercise radionuclide ventriculography for clinical evaluation of suspected ischaemic heart disease. Twenty four of the 38 had important $(>50 \%$ luminal obstruction) coronary artery disease on coronary cineangiography. Two patients had normal coronary cineangiograms but had evidence of cardiomyopathy with resting left ventricular dysfunction at cardiac catheterisation. The remaining 12 patients did not have cardiac catheterisation. Table 1 shows the findings at cardiac catheterisation and the clinical impression of each patient. Drug treatment was not stopped before exercise testing.

\section{RADIONUCLIDE ANGIOGRAPHY}

Radionuclide gated blood pool ventriculography was performed at rest and during symptom-limited supine bicycle (Quinton, Inc) exercise after in vivo labelling of red blood cells with $20 \mathrm{mCi}$ of technetium - $99 \mathrm{~m}$ pertechnetate. Exercise was started at $33.4 \mathrm{~W}$ and increased every three minutes by $33.4 \mathrm{~W}$ until symptoms occurred. Electrocardiographic gated data were acquired in the two minute period immediately before an increase in workload with a modified left anterior oblique projection and subsequent processing and determination of left ventricular ejection fraction at rest and during peak exercise by commercially available computer software (General Electric Medical

Table Raw data obtained from groups $1-4$

\begin{tabular}{|c|c|c|c|c|c|c|c|c|c|c|c|c|c|}
\hline \multirow[b]{2}{*}{ Patient } & \multicolumn{6}{|l|}{ Rest } & \multirow[b]{2}{*}{ Cath } & \multicolumn{6}{|c|}{ Exercise } \\
\hline & $\begin{array}{l}H R \\
(b / m)\end{array}$ & $\begin{array}{l}S B P \\
(m m H g)\end{array}$ & $\begin{array}{l}V \\
(m / s)\end{array}$ & $\begin{array}{l}A \\
\left(\mathrm{~m} / \mathrm{s}^{2}\right)\end{array}$ & $\begin{array}{l}S V \\
(\mathrm{ml} / \text { beat })\end{array}$ & $\begin{array}{l}E F \\
(\%)\end{array}$ & & $\begin{array}{l}H R \\
(b / m)\end{array}$ & $\begin{array}{l}S B P \\
(m m H g)\end{array}$ & $\begin{array}{l}V \\
(m / s)\end{array}$ & $\begin{array}{l}A \\
\left(\mathrm{~m} / \mathrm{s}^{2}\right)\end{array}$ & $\begin{array}{l}S V \\
(\mathrm{ml} / \text { beat })\end{array}$ & $\begin{array}{l}E F \\
\left(\begin{array}{l}0 \\
0\end{array}\right)\end{array}$ \\
\hline
\end{tabular}

\begin{tabular}{|c|c|c|c|c|c|c|c|c|c|c|c|c|c|}
\hline \multicolumn{14}{|c|}{ Group 1 rest $E F \geqslant 50 \%, \triangle E F \geqslant 5 \%(n=9)$} \\
\hline 1 & 60 & 160 & 0.93 & $8 \cdot 5$ & 113 & 56 & 0 VCAD & 114 & 215 & 0.93 & 8.5 & 131 & 67 \\
\hline 2 & 60 & 115 & 0.78 & $8 \cdot 7$ & 95 & 66 & 1 VCAD & 130 & 299 & $1 \cdot 15$ & $12 \cdot 8$ & 134 & 74 \\
\hline 3 & 82 & 150 & 0.99 & $11 \cdot 0$ & 116 & 52 & 0 VCAD & 94 & 178 & $1 \cdot 12$ & $14 \cdot 0$ & 119 & 66 \\
\hline 4 & 78 & 122 & 0.61 & $9 \cdot 4$ & 86 & 79 & 1 VCAD & 120 & 194 & $1 \cdot 15$ & 16.4 & 109 & 88 \\
\hline 5 & 78 & 132 & 0.88 & $8 \cdot 8$ & 129 & 63 & 3 VCAD & 126 & 212 & 1.0 & 12.5 & 137 & 75 \\
\hline 6 & 64 & 160 & 0.55 & $9 \cdot 2$ & 100 & 56 & 2 VCAD & 104 & 190 & 0.8 & $13 \cdot 3$ & 137 & 65 \\
\hline 7 & 66 & 160 & 0.5 & $6 \cdot \overline{3}$ & 74 & 63 & - & 96 & 180 & 0.65 & $10 \cdot 8$ & 82 & 71 \\
\hline 8 & 60 & 125 & 0.55 & $7 \cdot 9$ & 77 & 61 & $1 \mathrm{VCAD}$ & 96 & 135 & 0.75 & 13.6 & 94 & 66 \\
\hline 9 & 54 & 135 & 0.95 & 7.92 & 135 & 59 & - & 96 & 180 & $1 \cdot 3$ & $11 \cdot 8$ & 135 & 70 \\
\hline
\end{tabular}

\begin{tabular}{|c|c|c|c|c|c|c|c|c|c|}
\hline & & & & \multicolumn{6}{|c|}{ Group 2 rest $E F \geqslant 50 \%, \triangle E F<5 \%(n=14)$} \\
\hline 10 & 48 & 190 & 0.6 & $9 \cdot 2$ & 83 & 59 & - & 90 & 208 \\
\hline 11 & 67 & 160 & 0.7 & $8 \cdot \overline{8}$ & 95 & 66 & - & 110 & 1 \\
\hline 12 & 70 & 150 & 0.9 & $8 \cdot 2$ & 100 & 54 & 2 VCAD & 110 & \\
\hline 13 & 66 & 174 & 0.65 & $9 \cdot 3$ & 82 & 70 & - & 110 & \\
\hline 14 & 90 & 182 & 1.25 & $17 \cdot 9$ & 161 & 93 & AR & 130 & \\
\hline 15 & 59 & 160 & 0.95 & $8 \cdot 6$ & 134 & 68 & 2 VCAD & 109 & \\
\hline 16 & 54 & 148 & 0.89 & $8 \cdot 9$ & 111 & 61 & - & 145 & \\
\hline 17 & 94 & 168 & 0.7 & 1.0 & 99 & 60 & 2 VCAD & 121 & \\
\hline 18 & 60 & 162 & 0.88 & $9 \cdot 8$ & 104 & 88 & - & 110 & \\
\hline 19 & 70 & 124 & 0.88 & $12 \cdot 6$ & 113 & 52 & 1 VCAD & 130 & \\
\hline 20 & 65 & 145 & 0.9 & $8 \cdot 6$ & 127 & 57 & 2 VCAD & 114 & \\
\hline 21 & 75 & 125 & 0.81 & $13 \cdot 5$ & 107 & 60 & - & 114 & \\
\hline 22 & 60 & 160 & 0.69 & 13.8 & 117 & 66 & 1 VCAD & 110 & \\
\hline 23 & 66 & 160 & $0 \cdot 88$ & $8 \cdot 0$ & 126 & 60 & 2 VCAD & 140 & \\
\hline
\end{tabular}

$\begin{array}{llrrl}208 & 0.6 & 9 \cdot 2 & 78 & 57 \\ 190 & 0.8 & 10.0 & 87 & 65 \\ 180 & 0.83 & 8.7 & 91 & 48 \\ 230 & 0.75 & 13.6 & 81 & 71 \\ 260 & 1.1 & 18.0 & 130 & 81 \\ 182 & 1.0 & 11.8 & 129 & 72 \\ 220 & 1.06 & 11.8 & 112 & 60 \\ 190 & 0.7 & 10.0 & 88 & 56 \\ 224 & 0.84 & 12.0 & 104 & 83 \\ 194 & 0.93 & 15.5 & 94 & 50 \\ 190 & 1.0 & 11.1 & 149 & 61 \\ 165 & 0.61 & 11.6 & 80 & 51 \\ 190 & 0.78 & 15.6 & 120 & 62 \\ 234 & 1.0 & 14.0 & 131 & 63\end{array}$

\begin{tabular}{|c|c|c|c|c|c|c|c|c|c|c|c|c|c|}
\hline \multicolumn{14}{|c|}{ Group 3 rest $E F<50 \%, \triangle E F \geqslant 5 \%(n=7)$} \\
\hline $\begin{array}{l}24 \\
25 \\
26 \\
27 \\
28 \\
29 \\
30\end{array}$ & $\begin{array}{l}66 \\
72 \\
80 \\
51 \\
75 \\
66 \\
65\end{array}$ & $\begin{array}{l}110 \\
142 \\
120 \\
138 \\
112 \\
165 \\
120\end{array}$ & $\begin{array}{l}0.75 \\
0.55 \\
0.95 \\
0.55 \\
0.7 \\
0.78 \\
0.5\end{array}$ & $\begin{array}{l}7 \cdot 5 \\
7 \cdot 9 \\
9 \cdot 5 \\
7 \cdot 9 \\
8 \cdot 3 \\
6 \cdot 5 \\
7 \cdot 14\end{array}$ & $\begin{array}{r}112 \\
64 \\
118 \\
78 \\
102 \\
123 \\
123 \\
67\end{array}$ & $\begin{array}{l}29 \\
35 \\
49 \\
42 \\
35 \\
47 \\
32\end{array}$ & $\begin{array}{l}\text { S/PCABG } \\
1 \text { VCAD } \\
\text { CM } \\
3 \text { VCAD } \\
\text { S/PCABG } \\
\text { S/P CABG }\end{array}$ & $\begin{array}{l}115 \\
100 \\
140 \\
120 \\
120 \\
126 \\
100\end{array}$ & $\begin{array}{l}152 \\
156 \\
210 \\
175 \\
154 \\
218 \\
150\end{array}$ & $\begin{array}{l}0.8 \\
0.65 \\
1.1 \\
0.7 \\
0.8 \\
0.9 \\
0.78\end{array}$ & $\begin{array}{r}8 \cdot 9 \\
10 \cdot 0 \\
12 \cdot 2 \\
10 \cdot 0 \\
9 \cdot 4 \\
8 \cdot 2 \\
13 \cdot 0\end{array}$ & $\begin{array}{r}126 \\
62 \\
137 \\
83 \\
92 \\
145 \\
74\end{array}$ & $\begin{array}{l}38 \\
43 \\
64 \\
49 \\
44 \\
55 \\
43\end{array}$ \\
\hline \multicolumn{14}{|c|}{ Group 4 rest $E F<50 \%, \triangle E F<5 \%(n=5)$} \\
\hline $\begin{array}{l}31 \\
32 \\
33 \\
34 \\
35\end{array}$ & $\begin{array}{l}66 \\
90 \\
50 \\
67 \\
62\end{array}$ & $\begin{array}{l}168 \\
120 \\
140 \\
120 \\
147\end{array}$ & $\begin{array}{l}0.45 \\
0.45 \\
0.6 \\
0.63 \\
0.84\end{array}$ & $\begin{array}{r}5.0 \\
7.5 \\
5.5 \\
7.8 \\
12.0\end{array}$ & \begin{tabular}{r|}
68 \\
60 \\
74 \\
102 \\
93
\end{tabular} & $\begin{array}{l}27 \\
25 \\
41 \\
34 \\
37\end{array}$ & $\begin{array}{l}2 \text { VCAD } \\
\text { S/PCABG } \\
2 \text { VCAD } \\
3 \text { VCAD }\end{array}$ & $\begin{array}{r}130 \\
110 \\
70 \\
125 \\
94\end{array}$ & $\begin{array}{l}260 \\
145 \\
190 \\
182 \\
156\end{array}$ & $\begin{array}{l}1.1 \\
0.51 \\
0.65 \\
0.7 \\
0.83\end{array}$ & $\begin{array}{r}18.0 \\
7.3 \\
5.9 \\
10.0 \\
11.9\end{array}$ & $\begin{array}{r}130 \\
59 \\
80 \\
74 \\
85\end{array}$ & $\begin{array}{l}31 \\
29 \\
37 \\
38 \\
36\end{array}$ \\
\hline
\end{tabular}

HR, heart rate; SBP, systolic blood pressure; V, peak velocity; A, acceleration; SV, stroke volume; EF, ejection fraction; Cath, number of coronary arteries found to have $>50 \%$ luminal obstruction at cardiac catheterisation, VCAD, $0-3$ vessel coronary artery disease. AR, aortic regurgitation; S/P CABG, state after coronary artery bypass grafting; CM, cardiomyopathy. 
Systems PAGE Software and a General Electric Medical Systems STAR computer). The ventriculograms were interpreted blindly without knowledge of Doppler or catheterisation data.

\section{ECHOCARDIOGRAPHY}

Doppler echocardiograms were performed at rest and at peak exercise simultaneously with radionuclide ventriculography. A small $2 \mathrm{MHz}$ dedicated non-imaging Doppler transducer (Johnson and Johnson Irex Medical Systems) was hand held in the suprasternal notch. Both pulsed (gated to place the sample volume $7-10 \mathrm{~cm}$ away from the suprasternal notch) and continuous wave recordings were obtained. Both audio and graphic outputs were monitored while the Doppler transducer was angled anteriorly and to the right in the suprasternal notch to locate peak velocity envelopes with a crisp sound and consistent, distinct borders. Permanent recordings were made on videotape and on a strip chart recorder running at 50 or $100 \mathrm{~mm} / \mathrm{s}$. Pulsed Doppler was used primarily to ensure proper orientation of the transducer to record ascending aortic flow. Continuous wave recordings were used for quantitation.

Cross sectional echo-directed $\mathrm{M}$ mode recordings of the aortic annulus were obtained at the point of maximum opening of the aortic valve leaflets by standard techniques. Because the dimensions of the aortic annulus do not change significantly over a wide range of cardiac outputs, ${ }^{12}$ and because cross sectional echocardiograms of the aortic annulus cannot be recorded simultaneously with Doppler recordings from the suprasternal notch, cross sectional echocardiograms were recorded only at rest.

\section{DATA REDUCTION}

Doppler and cross sectional echocardiographic data were analysed by one observer who was unaware of the group to which individuals belonged. Previous studies in our laboratory ${ }^{6}$ have shown inter and intra observer variability of $<10 \%$ for these measurements. The peak velocity of flow in the ascending aorta (V Peak $(\mathrm{m} / \mathrm{sec})$ ) was determined from an average of 5-10 cardiac cycles and defined as the point on the Doppler spectral display showing the maximum velocity of flow. The time taken to reach peak velocity ( $\mathrm{T}$ Peak (s)) was measured as the time taken from the onset of flow to reach V Peak. Acceleration (A $(\mathrm{m} / \mathrm{s} / \mathrm{s}))$ was then calculated as:

$$
\mathrm{A}(\mathrm{m} / \mathrm{s} / \mathrm{s})=\mathrm{V} \mathrm{Peak}(\mathrm{m} / \mathrm{s}) / \mathrm{T} \text { Peak }(\mathrm{s})
$$

The area of the aortic valve orifice $\left(\mathrm{A}\left(\mathrm{cm}^{2}\right)\right)$ was measured by the method validated by Ihlen et al. ${ }^{13}$ The diameter of the aortic annulus from leading edge to leading edge at the onset of the QRS and the diameter at the peak of the $T$ wave were averaged to calculate the aortic orifice area.
The systolic velocity integral (SVI) was obtained from the Doppler recordings by an automated analysis system (Microsonics) that traced the envelope of maximal systolic velocity. Stroke volume was then calculated as:

$$
\mathrm{SV}\left(\mathrm{cm}^{3}\right)=\mathrm{SVI}(\mathrm{cm}) \times \mathrm{A}\left(\mathrm{cm}^{2}\right)
$$

\section{DATA ANALYSIS}

The patients were divided into four groups according to their resting ejection fractions and responses to exercise: in group 1 patients the resting ejection fraction was normal $(\geqslant 50 \%)$ and the ejection fraction during exercise increased normally (by $\geqslant 5 \%$ ); group 2 patients had normal resting ejection fractions $(\geqslant 50 \%)$ but the ejection fraction during exercise either fell or rose by $<5 \%$; group 3 patients had an abnormal resting ejection fraction $(<50 \%)$ and the ejection fraction during exercise rose by $\geqslant 5 \%$; and group 4 patients had abnormal resting ejection fractions $(<50 \%)$ and the ejection fraction during exercise either fell or rose by $<5 \%$.

\section{STATISTICAL METHODS}

The mean and standard deviation was used to summarise groups of data points. The mean of a study variate (peak velocity of flow (v), acceleration of flow (A), stroke volume (SV), heart rate (HR), and systolic blood pressure (SBP) at rest was compared with the mean at exercise and paired $t$ tests were used for each group.

For each variate the mean changes from rest to exercise for the four groups were assessed with a one way analysis of variance. When the $F$ test was significant $(p<0.003$ for $A, p<0.0005$ for SV, and $\mathrm{p}<0.0001$ for $\mathrm{V}$ ) the least significant difference $(\mathrm{LSD})^{12}$ procedure was used to compare pairs of mean changes and the probability level of each LSD comparison was given. When the $F$ test was not significant ( $p>0.5$ for HR, $p>0.9$ for SBP, and p > 0.6 for $\mathrm{HR} \times \mathrm{SBP}$ ), multiple comparisons were judged not significant (NS).

Simple linear regression analysis was used to relate exercise induced changes in peak velocity, acceleration, and stroke volume to changes in ejection fraction.

\section{Results}

The table lists the resting and exercise ejection fractions and the maximum heart rate and blood pressure and double product achieved during exercise for each individual patient together with Doppler derived acceleration, peak velocity, and stroke volume. No significant difference was seen between the increase in heart rate and blood pressure during exercise in the four groups. 
Figure 1 shows an example of Doppler recordings of blood flow in the ascending aorta obtained at rest and during maximum exercise. Good quality Doppler echocardiograms were obtained both at rest and during peak exercise in $35(92 \%)$ of the 38 patients. Examinations were generally easy to perform. There were few problems with exercise induced motion of the chest, and hyperventilation did not interfere with recording from the suprasternal notch. Adequate Doppler echocardiograms could not be obtained in three patients. Two of these failures were in obese patients with short necks that prevented access to the suprasternal notch even at rest. The cause of failure in the third patient was uncertain.

Figures 2 and 3 show individual values for acceleration and peak velocity of flow and stroke volume at rest and during exercise for the four groups of patients. The means and standard deviations for each group are also shown. In group 1 (fig 2), those with normal resting ejection fractions whose ejection fraction rose $\geqslant 5 \%$ during exercise, acceleration rose from $8.2(1.0) \mathrm{m} / \mathrm{s} / \mathrm{s}$ to $12.8(1.9) \mathrm{m} / \mathrm{s} / \mathrm{s}$ during exercise $(\mathrm{p}<0.01)$. Peak velocity of flow increased from $0.7(0.2) \mathrm{m} / \mathrm{s}$ at rest to $1.0(0.2) \mathrm{m} / \mathrm{s}$ at exercise $(\mathrm{p}<0.01)$ and stroke volume increased from 102.8 $(21.0) \mathrm{ml}$ to $123.0(25.0) \mathrm{ml}(\mathrm{p}<0.01)$.

In group 2 (fig 2), those patients with normal resting ejection fractions of $\geqslant 50 \%$ in whom the ejection fraction either fell or increased $<5 \%$, acceleration also increased from rest $(10.5(2.9) \mathrm{m} / \mathrm{s} / \mathrm{s})$ to exercise $(12.4(2.7) \mathrm{m} / \mathrm{s} / \mathrm{s})(\mathrm{p}<0.01)$, but the increase was significantly less $(p<0.01)$ than the increase demonstrated by patients in group 1 . Peak velocity was similar at rest $(0.8(0.2) \mathrm{m} / \mathrm{s})$ and exercise $(0.9$ $(0.2) \mathrm{m} / \mathrm{s})(\mathrm{NS})$. Stroke volume at rest was $111.4 \mathrm{ml}$ -not significantly different from that present during exercise (105.3 (23) $\mathrm{ml}$ ) (NS). The response of both peak velocity and stroke volume to exercise was significantly different from that seen in patients in group 1.

In group 3 (fig 3), those patients with abnormal

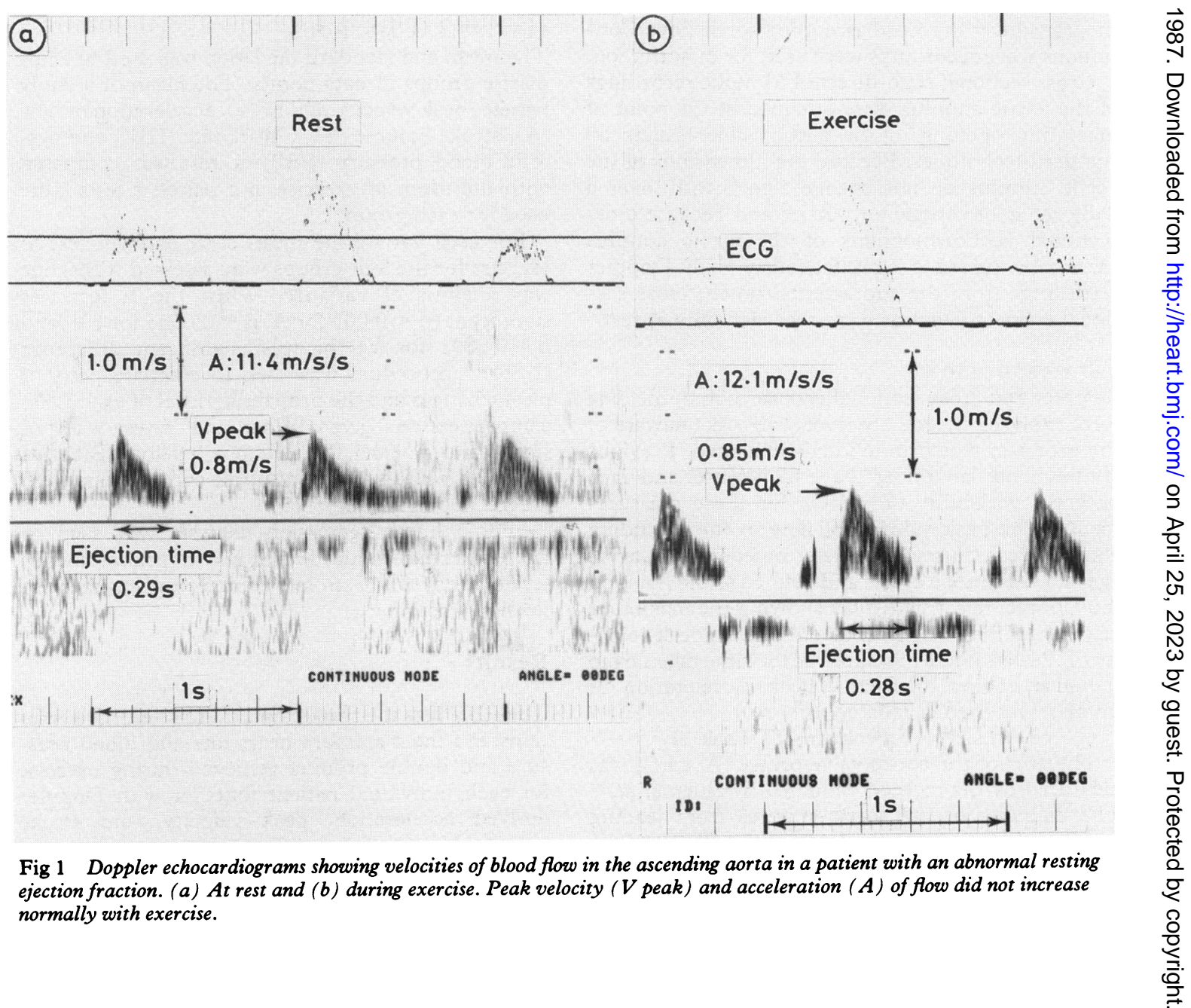



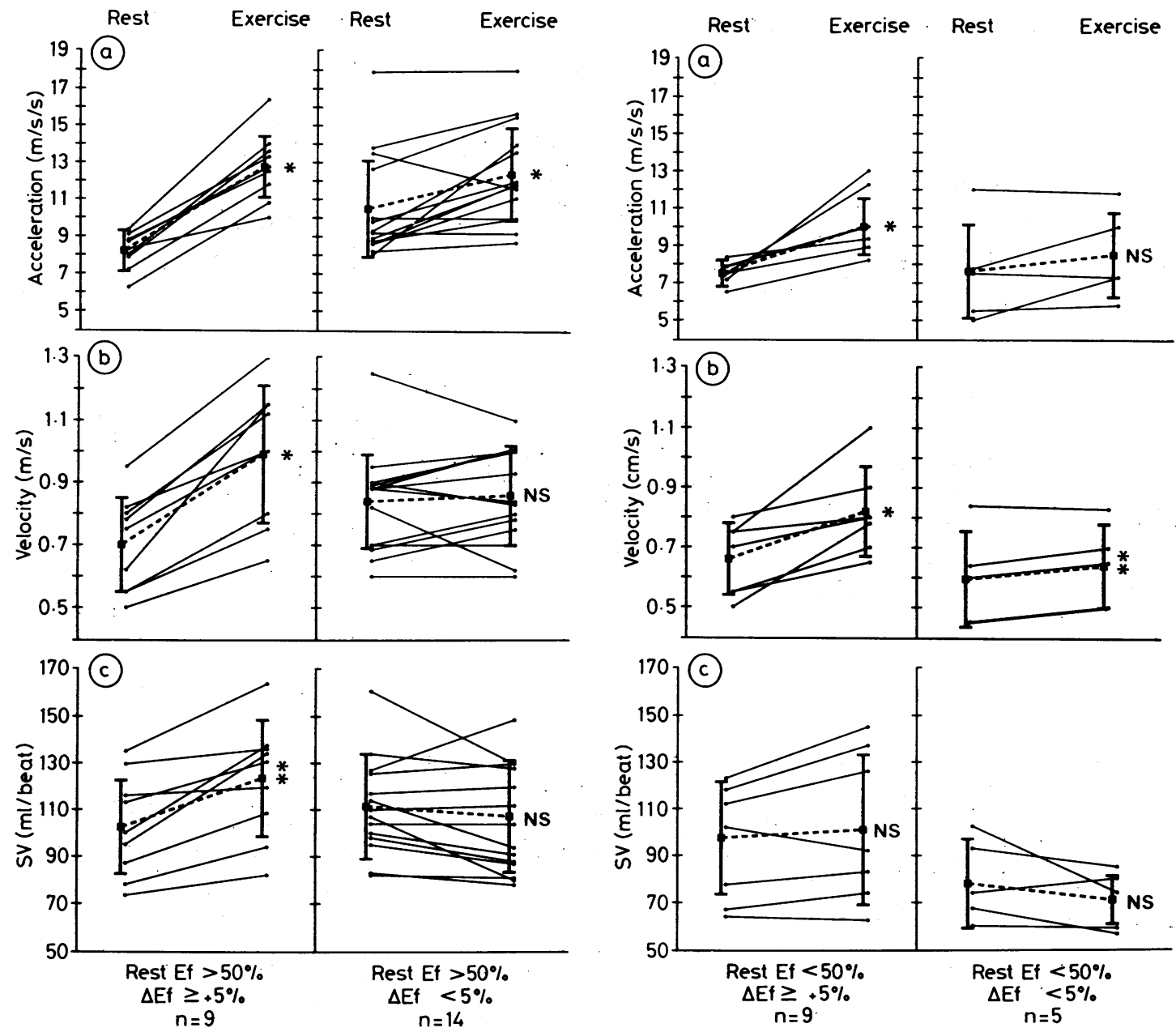

Fig 2 Individual values and mean (SD) at rest and exercise in groups 1 and 2 for $(a)$ acceleration of flow, $(b)$ peak velocity of flow, and (c) stroke volume. ${ }^{\star} p<0.01$; ${ }^{\star \star} p<0.05$. Ef, ejection fraction.
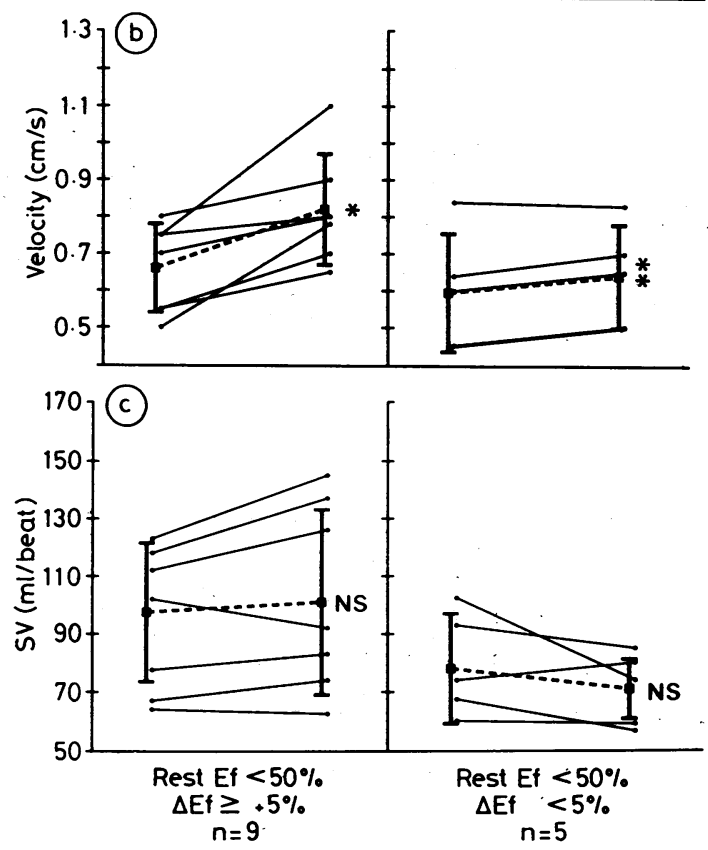

Fig 3 Individual values and mean (SD) at rest and exercise in groups 3 and 4 for (a) acceleration of flow, (b) peak velocity of flow, and (c) stroke volume. Ef, ejection fraction.

resting ejection fractions of $<50 \%$ who increased their ejection fractions $\geqslant 5 \%$ during exercise, resting acceleration was $7.5(0.6) \mathrm{m} / \mathrm{s} / \mathrm{s}$ and peak velocity was $0.7(0.1) \mathrm{m} / \mathrm{s}$. Both rose significantly during exercise, with acceleration increasing to $10 \cdot 2 \mathrm{~m} / \mathrm{s} / \mathrm{s}$ $(\mathrm{p}<0.001)$ and peak velocity to $0.8(0.2) \mathrm{m} / \mathrm{s}$ $(\mathrm{p}<0.001)$. Stroke volume at rest was $94.8(24 \cdot 8) \mathrm{ml}$ and did not rise significantly during exercise $(102 \cdot 7$ $(32 \cdot 9) \mathrm{ml})(\mathrm{p}=\mathrm{NS})$. Although both acceleration and peak velocity increased during exercise in this group, the increase was significantly less than the increase seen in patients in group 1 , those with normal resting ejection fractions whose ejection fraction increase $\geqslant 5 \%$ during exercise $(p>0.05)$. Although stroke volume did not increase, the

response was not significantly different from that seen in group $1(p=N S)$.

In patients in group 4 (fig 3), those with abnormal resting ejection fractions of $<50 \%$ whose ejection fraction fell further or increased by $<5 \%$ during exercise, acceleration at rest $(7.6(2 \cdot 8) \mathrm{m} / \mathrm{s} / \mathrm{s})$ failed to increase significantly during exercise $(8.5(2.4) \mathrm{m} / \mathrm{s} / \mathrm{s}$ $(\mathrm{p}=\mathrm{NS})$. Peak velocity rose from $0.59(0.2) \mathrm{m} / \mathrm{s}$ at rest to $0.64(0.1) \mathrm{m} / \mathrm{s}$ during exercise $(p<0.05)$ while stroke volume at rest $(79.4 \mathrm{ml})$ did not increase significantly with exercise (NS). The increase in peak velocity and stroke volume in this group was significantly less than the response of those patients in group 2 who had an abnormal resting ejection fraction of $<50 \%$ and an increase in ejection 
fraction of $\geqslant 5 \%$ during exercise. The change in acceleration in the two groups was similar (NS). No significant difference was found in the change in acceleration, peak velocity, or stroke volume during exercise between the two groups ( 2 and 4$)$ whose ejection fraction fell or rose $<5 \%$ during exercise (NS) regardless of resting ejection fraction.

Figure 4 compares the exercise induced change in ejection fraction with the change in acceleration of blood flow in the ascending aorta $(y=2.0 x-1.0$, $r=0.81, p<0.001$, SEE 5.16). Similarly, fig 5 compares the change in the acceleration of flow associated with exercise with the change in the ejection fraction ( $y=36.3 x-0.6, r=0.79, p<0.001$, SEE 4.08 ) and fig 6 compares the change in stroke volume with the change in ejection fraction $(y=0.3 x+2 \cdot 8$, $r=0.67, p<0.001$, SEE 4.95). Exercise ejection fraction correlated with exercise peak velocity $(y=50 x+16, r=0.64)$ and with exercise acceleration $(y=3.7 x+15, r=0.65)$.

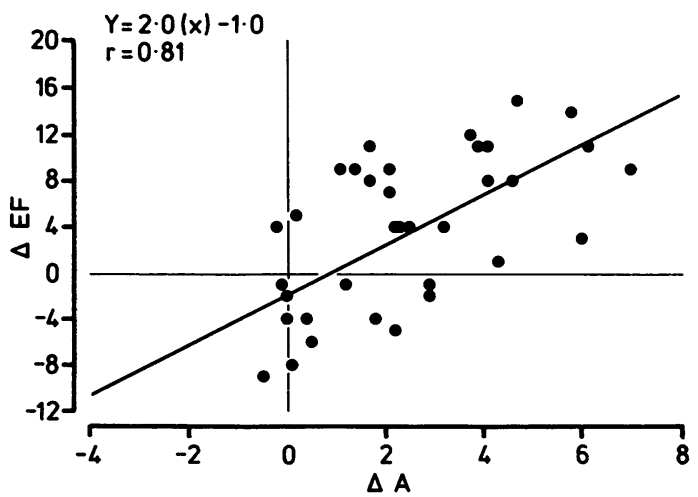

Fig 4 Change in ejection fraction ( $\triangle E F$ ) from rest to exercise compared with the change in acceleration $(\triangle A)$. $p<0.001, S E E 5 \cdot 16$.

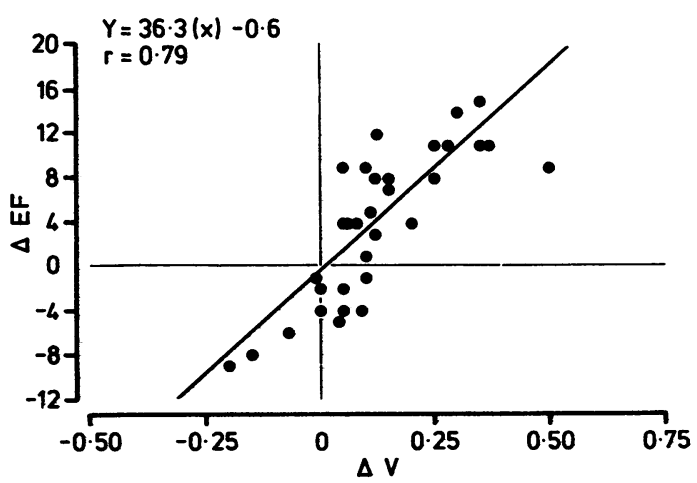

Fig 5 Change in ejection fraction $(\triangle E F)$ from rest to exercise compared with the change in peak velocity $(\Delta V)$. $p<0.001, S E E 4.08$.

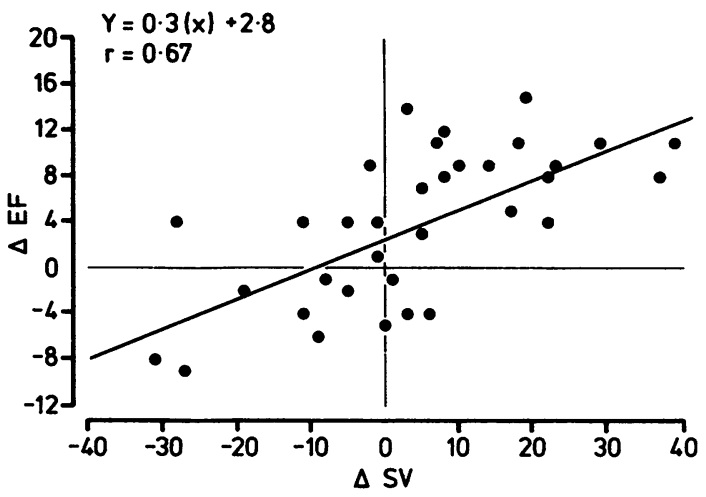

Fig 6 Change in ejection fraction ( $\triangle E F$ ) from rest to exercise compared with the change in stroke volume $(\triangle S V)$. $p<0.001, S E E 4.95$.

\section{Discussion}

This study demonstrates that technically adequate Doppler echocardiographic recordings of blood flow in the ascending aorta can be obtained both at rest and during exercise in a high proportion (92\%) of patients undergoing evaluation for suspected ischaemic heart disease. The use of a small dedicated Doppler transducer positioned in the suprasternal notch avoids many of the problems caused by hyperventilation and chest wall motion that make $M$ mode and cross sectional echocardiography somewhat difficult to perform during exercise. ${ }^{15}$ In addition, the Doppler recordings are relatively easy to analyse and quantitative information is quickly available.

To test the hypothesis that Doppler echocardiographic recordings of blood flow in the ascending aorta can detect exercise induced changes in left ventricular performance during exercise, patients were divided into four groups according to their resting left ventricular ejection fractions and the change in ejection fraction during exercise. Patients in group 1 had normal resting ejection fractions that increased normally during exercise. All three Doppler variables, acceleration, peak velocity, and stroke volume, increased during exercise in these patients proving that this method can show normal increases in left ventricular performance during exercise.

The remaining three groups were all abnormal because of either an abnormal resting ejection fraction or failure to increase their ejection fractions normally during exercise. In group 2, patients with normal resting ejection fractions whose ejection fraction failed to increase during exercise, acceleration also increased during exercise but the increase was significantly less than that of group 1. Peak velocity and stroke volume failed to increase. Thus 
failure of peak velocity and stroke volume to increase during exercise identified patients whose normal resting ejection fraction failed to increase normally during exercise and those in whom it did increase normally. Acceleration of flow did not increase as much in this group as it did in group 1.

Similar changes were seen in patients with abnormal resting ejection fractions. Acceleration and peak velocity both increased in patients in group 3, those with abnormal resting ejection fractions but normal increases in ejection fraction with exercise, but to a significantly lesser extent than in group 1 . Stroke volume was unchanged during exercise.

Neither acceleration nor stroke volume increased during exercise in patients in group 4, those with abnormal resting ejection fractions and failure to increase their ejection fractions during exercise. Peak velocity did increase but to a lesser extent than that of patients in group 3.

These results indicate that Doppler echocardiography of blood flow in the ascending aorta can detect exercise induced abnormalities in left ventricular function, at least as defined by radionuclide ventriculography. Although the groupings according to resting ejection fraction and change in ejection fraction during exercise were arbitrary and there is undoubtedly some variability in the determination of ejection fraction by radionuclide ventriculography, the magnitude of exercise induced changes in acceleration and peak velocity seemed to vary inversely with the degree of left ventricular dysfunction judged by the ejection fraction. Acceleration and peak flow increased most in group 1 and the increase progressively declined when group 2 was compared with group 1, group 3 with group 2, and group 4 with group 3 . As expected, the changes in stroke volume were not as closely related to the degree of left ventricular dysfunction.

Exercise induced changes in acceleration, peak velocity, and stroke volume were also compared directly with the change in ejection fraction. The best correlations were found between the change in acceleration and peak velocity and the change in ejection fraction; the correlation with the change in stroke volume was less strong. These findings further support the hypothesis that Doppler echocardiography of blood flow in the ascending aorta can detect exercise induced changes in global left ventricular performance.

Caution should be used before conclusions based on this data are extended. Left ventricular ejection fraction and flow in the ascending aorta are quite different manifestations of left ventricular performance. Their determinates are different and each is likely to be affected differently by changes in preload, afterload, and contractility. It was not the intent of this investigation to use Doppler recordings to predict changes in left ventricular ejection fraction in individual patients and indeed the considerable spread in these data indicates that this is probably not practical. Ejection fraction was used in this study only as an independent, clinically relevant marker of left ventricular function. Because of the fundamental differences between ejection fraction and aortic blood flow, it would have been surprising if the two had been more closely correlated.

Ideally, one would like to use this Doppler technique to predict the severity of coronary artery disease as related to the degree of exercise induced left ventricular dysfunction. While there is a trend to this effect in the patients in this study who underwent cardiac catheterisation, insufficient data are available to make this a firm conclusion. Exercise Doppler changes are, like the exercise ejection fraction, not specific for the detection of myocardial ischaemia but rather may reflect dysfunction with various causes.

This study confirms earlier work showing that the velocity profile of blood flow in the ascending aorta is related to left ventricular performance ${ }^{1-5}$ and indicates the practicality of non-invasively measuring flow in the ascending aorta during exercise with Doppler echocardiography; six changes in left ventricular performance precipitated by exercise can be detected by this technique. Further studies are needed to investigate more precisely the relation between left ventricular dysfunction and blood flow in the ascending aorta and to develop clinical application of Doppler echocardiography to detect left ventricular dysfunction both at rest and during exercise.

This study was supported in part by grants from the Veterans Administration, the American Heart Association of Wisconsin, and the National Institutes of Health/National Heart Lung and Blood Institute.

\section{References}

1 Light LH. Non-injurious ultrasonic technique for observing flow in the human aorta. Nature 1969; 224:1119-25.

2 Sequeira RF, Light LH, Cross G, Raftery EB. Transcutaneous aortovelography-a quantitative evaluation. Br Heart $J$ 1976;38:443-50.

3 Colocousis JS, Huntsman LL, Curreri PW. Estimation of stroke volume changes by ultrasonic Doppler. Circulation 1977;56:914-7.

4 Magnin PA, Stewart JA, Meyers S, Von Ramm O, Kisslo J. Combined Doppler and phased-array echocardiographic estimation of cardiac output. Circulation 1981;63:388-92.

5 Loeppky JA, Greene ER, Hockanga DE, Caprihan A, 
Luft UC. Beat-by-beat stroke volume assessment by pulsed Doppler in upright and supine exercise. $J$ Appl Physiol 1981;50:1173-82.

6 Daley. PJ, Sagar KB, Wann LS. Doppler echocardiographic measurement of flow velocity in the ascending aorta during supine and upright exercise. Br Heart J 1985;54:562-7.

7 Rushmer RF. Initial ventricular impulse-a potential key to cardiac evaluation. Circulation 1964;29: 268-81.

8 Noble MIM, Trenchard D, Guz A. Left ventricular ejection in conscious dogs-measurement and significance of the maximum acceleration of blood from the left ventricle. Circ Res 1966;19:139-47.

9 Gabe IT, Gault :JH, Ross J, et al. Measurement of instantaneous blood flow velocity and pressure in conscious man with a catheter-tip velocity probe. Circulation 1969;40:603-70.

10 Sabbah HN, Khaja F, Brymer JF, et al. Noninvasive evaluation of left ventricular performance based on peak acceleration measured with a continuous wave
Doppler velocity meter. Circulation 1986;74:323-9.

11 Bennett ED, Else W, Miller GAH, Sutton GC, Miller HC, Noble MIM. Maximum acceleration of blood from the left ventricle in patients with ischemic heart disease. Clin Sci Mol Med 1974;46:49-56.

12 Mehta N, Bennett D, Mannering D, et al. Usefulness of non-invasive Doppler measurement of ascending aortic blood velocity and acceleration in detecting impairment of the left ventricular functional response to exercise three weeks after acute myocardial infarction. Am J Cardiol 1986;58:879-84.

13 Ihlen H, Amlie JP, Dale J, et al. Determination of cardiac output by Doppler echocardiography. Br Heart $J$ 1984;51:54-60.

14 Milliken GA, Johnson DE. Analysis of messy data. Belmont, CA: Lifetime - Learning Publications, 1984:33.

15 Wann LS, Faris JV, Childress RH, Dillon JC, Weyman AE, . Feigenbaum $H$. Exercise crosssectional echocardiography in ischemic heart disease. Circulation 1979;60:1300-6. 